\title{
IRIDOID GLYCOSIDES FROM LINARIA GENISTIFOLIA (L.) MILL. IN BIOLOGICAL CONTROL OF SOIL-BORNE FUNGAL PATHOGENS OF WHEAT AND SOME STRUCTURE CONSIDERATIONS
}

\author{
Natalia Mashcenko ${ }^{a *}$, Angela Gurev ${ }^{\mathrm{a}}$, Galina Lupascu ${ }^{\mathrm{a}}$, Elena Gorincioi ${ }^{\mathrm{b}}$ \\ IInstitute of Genetics and Plant Physiology of Academy of Sciences of Moldova, 20, Padurii str., \\ Chisinau MD-2002, Republic of Moldova \\ ${ }^{b}$ Institute of Chemistry of Academy of Sciences of Moldova, 3, Academiei str. Chisinau MD-2028, Republic of Moldova, \\ "email: mne4747@mail.ru; tel: (+373 22) 5552 59; fax: (+373 22) 556180
}

This article is dedicated to the memory of Prof. Pavel Kintia

\begin{abstract}
Biological activity of the iridoid glycosides extract from Linaria genistifolia (L.) Mill. has been investigated, namely its influence on the resistance of the winter wheat Odesschi 51 plant to the caused by the Fusarium oxysporum and Helminthosporium avenae pathogenic fungi root rot. Our results indicate that summary iridoid glycosides from this plant, containing four major known compounds: 5-O-allosylantirrinoside, antirrinoside, linarioside and 6- $\beta$-hidroxiantirride, can be successfully employed in biological control of the afore-mentioned wheat pathogens: it stimulates wheat grains germination and embryonic root growth in conditions of fungal infection. ${ }^{1} \mathrm{H}$ and ${ }^{13} \mathrm{C}$ NMR characteristics of 5-O-allosylantirrinoside in Py- $d_{5}$ are for the first time presented. Structures of two conformers of 5-O-allosylantirrinoside in $\mathrm{D}_{2} \mathrm{O}$ and $\mathrm{Py}-d_{5}$ solutions are proposed, based on the experimental NMR evidence and molecular modelling studies.
\end{abstract}

Keywords: Linaria genistifolia (L.) Mill., iridoid glycosides, bioactivity, 5-O-allosylantirrinoside, NMR, molecular modelling.

Received: February 2015/Revised final: April 2015/Accepted: April 2015

\section{Introduction}

More than 200 species of genus Linaria (Scrophulariaceae) are representatives of wild flora, constituting a rich source of biologically active substances, such as flavonoids, iridoids, alkaloids, diterpenoids, glycosides and others. A series of beneficial physiological activities characterizes these medicinal plants of repute, explaining their wide application in folk and traditional medicine, as well as in homeopathic practice. Thus, different Linaria sp. have been used as tonics, antiscorbutics, laxatives, antidiabetics and diuretics, spasmolytics, cholagogic drugs, as well as for treatment of wounds, bladder catarrhs, haemorrhoids and vascular disorders [1-3].

The iridoid composition of L. dalmatica (L.) Mill., L. genistifolia (var. genistifolia and var. euxina) (L.) Mill., L. simplex (Wild.), L. pelisseriana, L. vulgaris and L. peloponnesiaca Bois \& Heldr., which occur in Bulgaria, has been in depth examined and reported by N. Handjieva, S. Popov et al. [4-6]. Structure elucidations have been carried out mainly by spectral methods and the data of pioneering studies on molecular mechanics calculations in this field were published [4]. An iridoid glycoside has been found amongst the chemical constituents of $L$. aucheri that is characteristic for the flora of Turkey [7]. The iridoid composition of L. japonica $\mathrm{M}_{\mathrm{IQ}}$, a Japanese folk medicine known as laxative and diuretic, has been investigated, detailed proton magnetic resonance examinations on the found iridoid glycosides and their derivatives being presented [8].

We have previously presented the results of our studies on biologically active compounds from Linaria vulgaris Mill. [9]. As an extension of this study we have now investigated the other species of Linaria, namely L. genistifolia (L.) Mill. that is widely distributed on the territory of Republic of Moldova, for the biological activity against soil-borne fungal pathogens of wheat $F$. oxysporum and $H$. avenae. These fungi are very spread, being known by severe affection of some vital processes in wheat plant, such as: seed germination, growth and development of the embryonic root and also infecting the grains with micro toxins, as well as reduction of the crop quantity and quality $[10,11]$.

\section{Results and discussion}

This study was carried out with an objective of investigation the antifungal activity potential of the iridoid glycosides extract (IGE) from L. genistifolia (L.) Mill. We have studied the properties of IGE from L. genistifolia (L.) Mill. on the resistance of the winter wheat Odesschi 51 plant to the root rot that is caused by the $F$. oxysporum and $H$. avenae pathogenic fungi. Our results indicate that summary iridoid glycosides from this plant can be successfully employed in biological control of the afore-mentioned wheat pathogens: it stimulates wheat grains germination and embryonic root growth in conditions of fungal infection.

In IGE four major known iridoids were identified, after chromatographic separation, their presence in $L$. genistifolia (L.) Mill. being previously described [4,6]. The structures of 5-O-allosylantirrinoside (1), which was the predominant IGE component, and $6 \beta$-hydroxyantirride (4) have been confirmed by means of NMR spectroscopy, as 
already reported [4,6], while antirrinoside (2) and linarioside (3) were identified by comparison of their physico-chemical properties with the literature data [8] (Figure 1).

The winter wheat Odesschi 51 constituted the object of the study. Prior to sowing, seeds of the winter wheat Odesschi 51 were soaked in IGE aqueous solutions having the mass fractions $10^{-5}, 10^{-4}, 10^{-3}, 10^{-2} \%$. As a control version the water soaked grains served. For comparison, a part of the grains was soaked in the same concentrations aqueous solutions of Moldstim - a certificated product for agricultural usage [12]. After drying the grains were soaked in $F$. oxysporum and $H$. avenae 21 days culture filtrates (CF) for 18 hours, then rinsed with distilled water and placed in a Petri dish, on filter paper moistened with distilled water. The seedlings were cultivated for 6 days at a temperature of $22^{\circ} \mathrm{C}$.

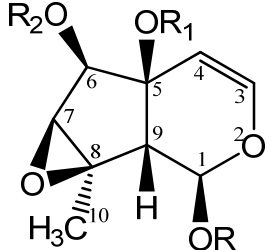

$1 \mathrm{R}=\beta$-D-Glc $\mathrm{R}_{1}=\beta$-D-All, $\mathrm{R}_{2}=\mathrm{H}$

$2 \mathrm{R}=\beta$-D-Glc; $\mathrm{R}_{1}=\mathrm{R}_{2}=\mathrm{H}$

$\mathrm{C}_{1}$ Hquasi-ax. [8]

$6 \mathrm{R}=\beta$-D-Glc $(\mathrm{OAc})_{4}$;

$\mathrm{R}_{1}=\mathrm{R}_{2}=$ Ac, $\mathrm{C}_{1}$ Hquasi-eq. [8]

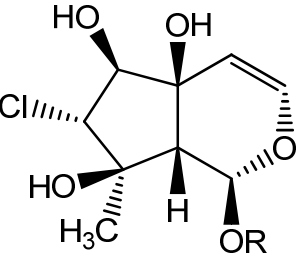

$3 \mathrm{R}=\beta$-D-Glc

$\mathrm{C}_{1}$ Hquasi-eq. [8]

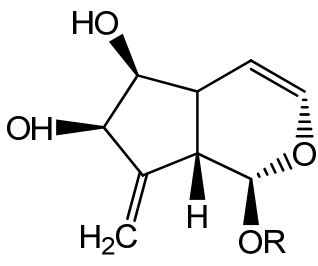

$4 \mathrm{R}=\beta$-D-Glc

$\mathrm{C}_{1}$ Heq. [4]

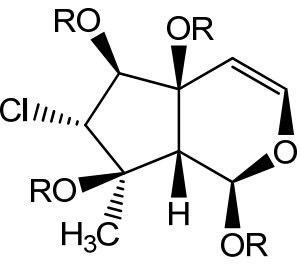

$5 \mathrm{R}=\beta$-D-Glc- $\left(\mathrm{O}\left(\mathrm{CH}_{3}\right)_{3} \mathrm{Si}\right)_{4}$ $\mathrm{C}_{1}$ Hquasi-ax. [8]

Figure 1. Structures of compounds $1-4$, the major IGE components, and obtained via synthesis compounds 5 and $6[8]$.

The plant response was assessed on the basis of its germination capacity and the length of embryonic root. The obtained results show that by infecting the grains with the $F$. oxysporum and $H$. avenae $\mathrm{CF}$, the seed germination is being diminished by 33.4 and $16.7 \%$, respectively, while the embryonic root is being reduced by 35.7 and $30.2 \%$, as compared to the control version (Tables 1 and 2). This proves the toxicity of the fungi that causes root rot. When treating the infected grains with Moldstim, the most efficient concentrations were in the range of $10^{-4} \ldots 10^{-3 \%}$; it caused an increase in the germination process by $3.4-11.7 \%$ and $9.7-18.4 \%$, and the augment of the length of embryonic root by $13.72-18.8 \%$ and $6.7-10.0 \%$, correspondingly, in comparison with the $F$. oxysporum and $H$. avenae $\mathrm{CF}$ versions. It was interesting to note the same beneficial effect of IGE from L. genistifolia (L.) Mill. on the infected wheat grains and to compare the furnished by both experimental protocols results. For instance, the IGE-treated and infected with $F$. oxysporum plants showed a germination level of $98.3 \%$, which is by $35 \%$ more, and a root longer by cca $27 \%$, when compared to $F$. oxysporum CF. (Table 1). These data speak in favour of higher biological activity of IGE versus Moldstim (about three times in the germination process and one and a half- in embryonic root elongation in the best versions, entries 4 and 8-9 in Table 1), the most efficacious IGE concentration being found also in the range of $10^{-4}-10^{-3} \%$.

Table 1

The influence of IGE on the winter wheat Odesschi 51 plant response to the Fusarium oxysporum culture filtrate.

\begin{tabular}{|c|c|c|c|c|}
\hline No. & Version/concentration, $\%$ & $\begin{array}{c}\text { Germination, } \\
\%\end{array}$ & $\begin{array}{l}\text { Embryonic root length, } \\
\mathrm{mm}\end{array}$ & $\begin{array}{c}\% \text { compared to } \\
\text { CF } \\
\text { F. oxysporum }\end{array}$ \\
\hline 1 & Control version $\left(\mathrm{H}_{2} \mathrm{O}\right)$ & 96.7 & $80.81 \pm 1.80$ & 155.5 \\
\hline 2 & CF F. oxysporum & 63.3 & $51.97 \pm 2.57$ & - \\
\hline 3 & CF F. oxysporum + Moldstim, $10^{-2}$ & 63.6 & $57.08 \pm 1.65^{*}$ & 109.8 \\
\hline 4 & CF F. oxysporum + Moldstim, $10^{-3}$ & 75.0 & $61.76 \pm 1.93 *$ & 118.8 \\
\hline 5 & CF F. oxysporum + Moldstim, $10^{-4}$ & 66.7 & $59.10 \pm 2.22 *$ & 113.7 \\
\hline 6 & CF F. oxysporum + Moldstim, $10^{-5}$ & 65.0 & $46.74 \pm 2.77$ & 89.9 \\
\hline 7 & CF F. oxysporum + IGE, $10^{-2}$ & 96.7 & $59.59 \pm 1.82 *$ & 114.7 \\
\hline 8 & CF F. oxysporum + IGE, $10^{-3}$ & 98.3 & $67.75 \pm 1.63^{*}$ & 130.4 \\
\hline 9 & CF F. oxysporum + IGE, $10^{-4}$ & 98.3 & $64.15 \pm 1.59^{*}$ & 123.4 \\
\hline 10 & CF F. oxysporum + IGE, $10^{-5}$ & 86.7 & $55.67 \pm 0.94$ & 107.1 \\
\hline
\end{tabular}

* true in relation to $F$. oxysporum $C F$ at $p \leq 0.05$. 
Similar effects can be observed in the presence of IGE in CF of the infected by $H$. avenae fungi grains of the winter wheat: the length of the embryonic root grows by $30.4 \%$ and germination by $13.3 \%$ (entries 9 and 8 in Table 2, IGE concentration $10^{-4}$ and $10^{-3 \%}$, respectively), in comparison with the $H$. avenae CF version (entry 2, Table 2). Thus, the IGE biological properties against $H$. avenae infection are rather comparable with the activity, exerted by Moldstim (about two times higher stimulation of root elongation and 1.3 times higher promotion of germination process (entries $5 / 9$ and $4 / 8$ in Table 2).

Table 2

The influence of IGE on the winter wheat Odesschi 51 plant response to the Helminthosporium avenae culture filtrate.

\begin{tabular}{clccc}
\hline No. & \multicolumn{1}{c}{ Version/concentration, $\%$} & Germination, $\%$ & $\begin{array}{c}\text { Embryonic root length, } \\
\text { mm }\end{array}$ & $\begin{array}{c}\text { \% compared to } \\
\text { CF } \\
\text { H. avenae }\end{array}$ \\
\hline 1 & Control version $\left(\mathrm{H}_{2} \mathrm{O}\right)$ & 96.7 & $80.81 \pm 1.80$ & 143.3 \\
2 & CF H.avenae & 80.0 & $56.38 \pm 2.59$ & - \\
3 & CF H.avenae + Moldstim, $10^{-2}$ & 86.7 & $58.54 \pm 1.25^{*}$ & 103.8 \\
4 & CF H.avenae + Moldstim, $10^{-3}$ & 90.0 & $61.82 \pm 0.98^{*}$ & 109.5 \\
5 & CF H.avenae + Moldstim, $10^{-4}$ & 86.7 & $66.75 \pm 1.14^{*}$ & 118.4 \\
6 & CF H.avenae + Moldstim, $10^{-5}$ & 85.0 & $59.92 \pm 2.11$ & 106.3 \\
7 & CF H.avenae + IGE, 10-2 & 83.3 & $65.40 \pm 1.60^{*}$ & 116.0 \\
8 & CF H.avenae + IGE, $10^{-3}$ & 93.3 & $69.32 \pm 1.44^{*}$ & 123.0 \\
9 & CF H.avenae + IGE, 10-4 & 83.3 & $73.52 \pm 2.40$ & 130.4 \\
10 & CF H.avenae + IGE, $10^{-5}$ & 90.0 & $67.9 \pm 2.04$ & 120.4 \\
\hline
\end{tabular}

* true in relation to $H$. avenae $C F$ at $p \leq 0.05$.

Thus, the achieved by us results indicate that the obtained from L. genistifolia (L.) Mill. iridoid glycosides can be successfully utilized as substances of natural origin that stimulate wheat grains germination and embryonic root growth, considering the infected by fungi grains [13]. Our data are particularly attractive in terms of availability of the iridoid glycosides source: L. genistifolia (L.) Mill. grows in spontaneous flora and can be collected in large quantities.

Broadening the range of natural biologically active and environmentally inoffensive fungicidal substances is a very actual issue for agricultural workers and researchers, since biological control of insect pests, plant pathogens and weeds, is the only alternative to the use of pesticides in agriculture and forestry.

It should be mentioned, that during confirmation the stereochemical structure of compounds $\mathbf{1}$ and $\mathbf{4}$ our attention was especially drawn to the reported individual NMR spectroscopic data of compounds, which prove the reliability of structure assignments. Thus, N. Handjieva et al. have established the structure and relative stereochemistry of $6 \beta$-hydroxyantirride 4 on the basis of spectral studies, corroborating the NMR experimental data by molecular mechanics calculations, by using Haasnoot equation [4,14]. The minimum-energy stereostructure of $\mathbf{4}$ and its analog with OMe instead of OGlc residue indicated that the conformation of the six-membered ring of aglycon is close to a halfchair with an axially oriented substituent at $\mathrm{C}-1$, which perfectly corresponded to the experimental $J_{1,9}$ value of 2.3-2.5 $\mathrm{Hz}$. The recorded by us in $\mathrm{D}_{2} \mathrm{O}{ }^{1} \mathrm{H}$ and ${ }^{13} \mathrm{NMR}$ spectra of $\mathbf{4}$ demonstrated identical NMR characteristics of our compound to the published one [4].

The prevailing in IGE component, compound $\mathbf{1}$ is quite widespread in the plants of the genus Linaria, being formerly found in five Linaria species [6], including the investigated by us specimen. Likewise, comparison of its ${ }^{1} \mathrm{H}$ and ${ }^{13} \mathrm{C}$ NMR spectral characteristics, proved its identity to the published 5-O-allosylantirrinoside 1 , when $\mathrm{D}_{2} \mathrm{O}$ was employed as NMR solvent, Table 3 [6]. The opportunity of NMR characterization of compound 1 in deuterated pyridine $\left(\mathrm{Py}-d_{5}\right)$ as a weakly interacting solvent has been by us considered, by this intending to update the information on solvent effects in its NMR data profile. It should be mentioned, that Py- $d_{5}$ presents some important advantages as NMR solvent, particularly, for investigations in the field of glycosides, namely: avoidance of the solvent interactions and signal overlapping, better solubility then in $\mathrm{D}_{2} \mathrm{O}$ or MeOD etc. But its use is limited by the high cost, $\mathrm{D}_{2} \mathrm{O}$ being much more attractive in terms of price.

The spectral data of compound 1, obtained after recording it's ${ }^{1} \mathrm{H}$ and ${ }^{13} \mathrm{C}$ NMR spectra in Py- $d_{5}$ were rather different from the obtained in $\mathrm{D}_{2} \mathrm{O}$ solution ones (Table 3). This was not so unusual, at first appearance, since it is a matter of common knowledge, that the nature of solvent can influence both ${ }^{1} \mathrm{H}$ and ${ }^{13} \mathrm{C}$ chemical shifts and spin - spin coupling constants of protons [15-17]. From the other side, the noted differences could be favorable to the structural identity either of an epimeric structure, possessing the opposite stereochemistry at $\mathrm{C}_{1}$ (i.e. $R$-configuration), or, in accordance to the data of I. Kitagawa et al. [8], to a conformer of $\mathbf{1}$. Since the configuration of the glucosyloxy moiety at $\mathrm{C}_{1}$ in antirrinoside 2 has been previously proved to be $\beta$ [18] (i.e., S-configuration), the possibility of examination the $\mathrm{C}_{1}$ 
epimer of 1 has been omitted. No evidence was found in the literature, regarding the dihydropyrane ring conformation of 5-O-allosylantirrinoside 1 [6], but the data are available for the conformers of its congeners: antirrinoside 2, linarioside 3 and some their synthetic derivatives [8]. In this light, clarifying the conformation of natural $\mathbf{1}$ has been planned, by analysis both the NMR spectroscopy and molecular modelling (MM) with energy minimization data, taking into account the traced by N. Handjieva et al. route [4].

The predominant molecule geometry of compound 2, four it's Me, Ac, TMS derivatives and hepta-Otrimethylsilyl-linarioside 5 involved quasi-axial orientation of $\mathrm{C}_{1}$ proton, for them the values of $J_{1,9}$ coupling constant varying from 5.5 to $10.5 \mathrm{~Hz}$, (spectra recorded in $\mathrm{D}_{2} \mathrm{O}, \mathrm{CDCl}_{3}$ and $\mathrm{CCl}_{4}$ ), as reported [8]. Whilst for linarioside 3, two it's acetates and hexaacetilated derivative of antirrinoside 2, compound $\mathbf{6}$, the quasi-equatorial position of proton at $\mathrm{C}-1$ has been assigned by the same authors on the basis of PMR evidence and Dreiding model inspection (e.g. for compound 3: 5.70 ppm (br.s.), $\mathrm{W}_{1 / 2}=2.0 \mathrm{~Hz}, \mathrm{C}_{1}-\mathrm{H}$; for compound 6: $2.77 \mathrm{ppm}$ (br.s.), $\left.\mathrm{W}_{1 / 2}=4.5 \mathrm{~Hz}, \mathrm{C}_{9}-\mathrm{H}\right)\left(\right.$ spectra recorded in $\mathrm{D}_{2} \mathrm{O}$ and $\mathrm{CDCl}_{3}$, respectively, at $60 \mathrm{MHz}$ ) [8].

On the basis of our experimental data and taking advantage of the formulated by the Japanese chemists observation, on the relation between the splitting pattern of proton at $\mathrm{C}_{9}$ and dihydropyrane ring conformation in $\mathbf{2}$ and its derivatives [8], we explain the discussed differences in NMR data of compound $\mathbf{1}$ in two mentioned NMR solvents by conformational difference of dihydropyrane ring, as well, judging by the values of $J_{1,9}$ vicinal coupling constants: 5.48 ppm, d, $J_{1,9}=6.8 \mathrm{~Hz}, \mathrm{C}_{1}$ ax. $\mathrm{H},\left(\mathrm{D}_{2} \mathrm{O}\right)$ versus $5.84 \mathrm{ppm}, \mathrm{d}, J_{1,9}=3.7 \mathrm{~Hz}, \mathrm{C}_{1}$ eq. $\mathrm{H}$, (Py- $\left.d_{5}\right)$, Table 3.

Interestingly, as it can be noted from the afore-mentioned, the nature of solvent proved no impact on the conformations of compounds $\mathbf{2}, \mathbf{3}$ and their derivatives [8]. However, in the case of the analyzed by us glycoside $\mathbf{1}$ change of the used NMR solvent causes, according to the established by us values of $J_{1,9}$ coupling constants, switching from one conformation to another.

The minimum-energy stereo-structures for the examined conformers of 5-O-allosylantirrinoside 1 have been obtained, which are depicted in Figure 2: 1a- in Py- $d_{5}$, and $\mathbf{1 b}$ - in $\mathrm{D}_{2} \mathrm{O}$, correspondingly, and the ${ }^{1} \mathrm{H} /{ }^{1} \mathrm{H}$ coupling constants have been calculated, by using molecular modelling with energy minimization software, namely PERCH NMR TOOLS (version 2014.1)). The results indicated on a good agreement between the calculated and experimental vicinal $J_{1,9^{-}}$ values in pyrenone ring of conformers $\mathbf{1 a}$ and $\mathbf{1 b}$ of $\mathbf{1}$. Thus, for conformer $\mathbf{1 a}$ the calculated value of $J_{19}$ is $3.12 \mathrm{~Hz}$ (experimental value $3.7 \mathrm{~Hz}$ ), while for $\mathbf{1 b}$ the calculated $J_{1,9}$ constitutes $10.84 \mathrm{~Hz}$ (experimental value $6.8 \mathrm{~Hz}$ ). The minimum-energy stereo-structures of both conformers $\mathbf{1 a}$ and $\mathbf{1 b}$ indicate that the conformations of the six-membered pyrenone ring is close to a half-chair, with an axially oriented substituent at $\mathrm{C}_{1}$ in $\mathbf{1 a}$ and an equatorially oriented substituent in $\mathbf{1 b}$. The recorded in Py- $d_{5}$ NOE experiments have demonstrated strong NOE interactions between $\mathrm{CH}_{3}-10$ and $\mathrm{C}_{1}-\mathrm{H}$, while in $\mathrm{D}_{2} \mathrm{O}$ these interactions were less pronounced, also supporting the indicated in Figure 2 structures of the conformers $\mathbf{1 a}$ and $\mathbf{1 b}$.

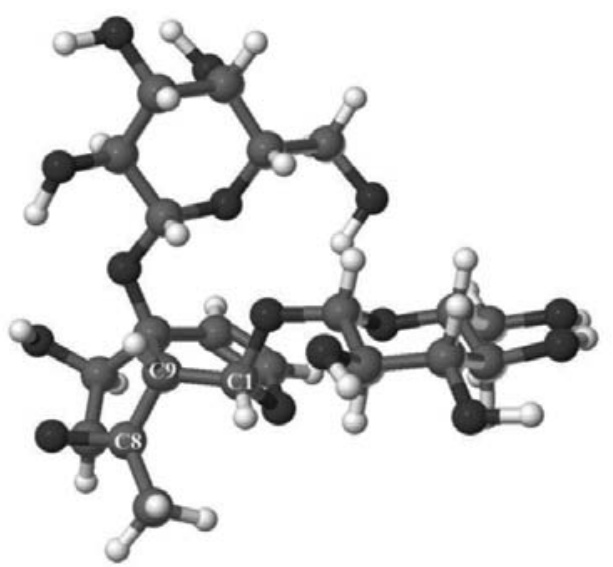

$1 \mathbf{a}$

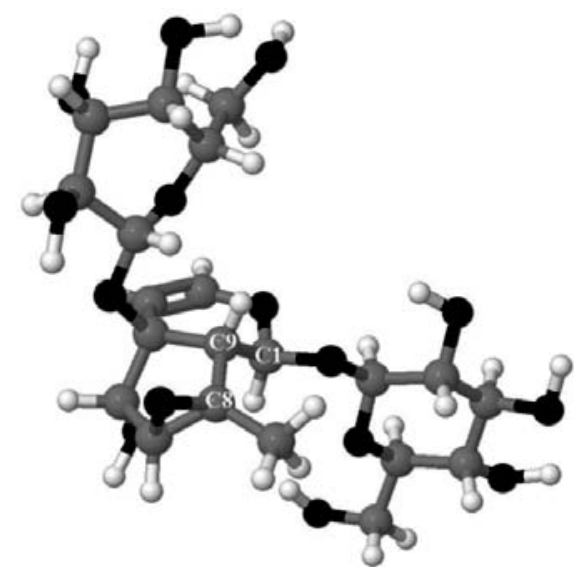

$1 \mathrm{~b}$

Figure 2. Minimum-energy conformations 1a and 1b of 5-O-allosylantirrinoside 1.

In the case of the pair of diastereoisomers of 1, hypothetic conformers of the epimer with the opposite stereochemistry at $\mathrm{C}_{1}$ (i.e. $R$-configuration), the calculated values of $J_{1,9}$ were very close, constituting 3.15 and $3.18 \mathrm{~Hz}$, thus confirming the only bigger value of $J_{1,9}$ for $\mathbf{1 b}$ and, implicitly, conclusions of Scarpati et al. [18].

Being occurred together in the same plant, question about conformational differences amongst compounds 1-4 in $\mathrm{D}_{2} \mathrm{O}$ solutions is of interest also from the biogenetic point of view, since water is the solvent of life. Thus, for the natural epoxide $\mathbf{2}$ and it's 5-O-allosyl ether $\mathbf{1}$, belonging to the antirrinoside iridoid type, the same conformation of dihydropirane ring of aglycon is adopted in $\mathrm{D}_{2} \mathrm{O}$, whereas for the corresponding to epoxide $\mathbf{2}$ clorohydrine $\mathbf{3}$ - the opposite one, which is characteristic also for the representative of the rare antirride type- compound $\mathbf{4}$, as depicted in Figure 1. 
Thus, putting together the results of our joint NMR-MM study, it can be concluded, that the noted differences in ${ }^{1} \mathrm{H}$ and ${ }^{13} \mathrm{C}$ NMR characteristics of compound $\mathbf{1}$ demonstrate solvent influence on the molecule geometry. Our data seem not to be in the same line with that of I. Kitagawa [8], in fact, completing them. According to the $\mathrm{MM}$ data, in $\mathrm{D}_{2} \mathrm{O}$ the conformer molecule is spatially more relaxed, being maximally available for hydration, whilst in Py- $d_{5}$ it is more compactly packed. Strong hydration of 5-O-allosylantirrinoside molecules, especially it's highly hydrophilic glucose and allose moieties, most likely exerts shielding effect upon ${ }^{1} \mathrm{H}$ and ${ }^{13} \mathrm{C}$ nuclei, causing their upfield shifts in $\mathrm{D}_{2} \mathrm{O}$ solution.

${ }^{1} \mathrm{H}$ and ${ }^{13} \mathrm{C}$ NMR spectral data for compound $1\left(\delta \mathrm{ppm}, J(\mathrm{~Hz})^{\mathrm{a}}\right.$.

Table 3

\begin{tabular}{|c|c|c|c|c|}
\hline \multirow[t]{2}{*}{$\mathrm{C} / \mathrm{H}$ atom } & \multicolumn{2}{|c|}{$P y-d_{5}$} & \multicolumn{2}{|c|}{$\mathrm{D}_{2} \mathrm{O}$} \\
\hline & $\delta_{H}^{b}$ & $\delta_{C}^{c}$ & $\delta_{H}^{b, d}$ & $\delta_{C}^{c, e}$ \\
\hline Aglycon & & & & \\
\hline 1 & $5.84 \mathrm{~d}, J=3.7$ & 93.1 & $5.48 \mathrm{~d}, J=6.8$ & 95.5 \\
\hline 3 & $6.64 \mathrm{~d}, J=6.4$ & 143.9 & $6.61 \mathrm{~d}, J=6.2$ & 144.8 \\
\hline 4 & $5.34 \mathrm{~d}, J=6.4$ & 105.2 & $5.12 \mathrm{~d}, J=6.2$ & 106.3 \\
\hline 5 & - & 80.5 & - & 80.4 \\
\hline 6 & $4.23 \mathrm{~d}, J=2.8$ & 75.9 & $4.30 \mathrm{~d}, J=1.9$ & 77.8 \\
\hline 7 & $3.46 \mathrm{~d}, J=2.8$ & 66.0 & $3.60 \mathrm{~d}, J=1.8$ & 66.0 \\
\hline 8 & - & 63.5 & - & 64.7 \\
\hline 9 & $3.10 \mathrm{~d}, J=3.7$ & 50.3 & $3.01 \mathrm{~d}, J=6.8$ & 50.5 \\
\hline 10 & $1.32 \mathrm{~s}$ & 17.4 & $1.51 \mathrm{~s}$ & 17.4 \\
\hline \multicolumn{5}{|l|}{ Glucose } \\
\hline 1 & $5.28 \mathrm{~d}, J=7.9$ & 98.3 & $4.82 \mathrm{~d}, J=8.0$ & 98.8 \\
\hline 2 ' & $4.05^{*}$ & 75.5 & $* *$ & 73.7 \\
\hline $3^{\prime}$ & $4.23^{*}$ & 77.6 & $* *$ & 76.4 \\
\hline 4 ' & $4.17 *$ & 72.1 & ** & 70.4 \\
\hline 5 ' & $3.98^{*}$ & 79.6 & $* *$ & 77.1 \\
\hline 6' & $4.40-4.50^{*}$ & 63.2 & $3.60-3.95$ & 61.8 \\
\hline \multicolumn{5}{|l|}{ Allose } \\
\hline $1 "$ & $5.70 \mathrm{~d}, J=7.9$ & 97.8 & $4.89 \mathrm{~d}, J=8.3$ & 96.5 \\
\hline $2 "$ & $4.00^{*}$ & 73.3 & $* *$ & 72.0 \\
\hline $3 "$ & $4.70 \quad \mathrm{t}, J=2.7$ & 72.9 & $4.19 \mathrm{t}, J=2.8$ & 71.0 \\
\hline $4 "$ & $4.28 *$ & 68.4 & $* *$ & 67.4 \\
\hline $5 "$ & $4.40^{*}$ & 76.9 & $* *$ & 74.3 \\
\hline 6" & $4.36-4.40 *$ & 62.6 & $3.60-3.85$ & 61.8 \\
\hline
\end{tabular}

${ }^{a}$ Assignments of ${ }^{1} \mathrm{H}$ and ${ }^{13} \mathrm{C}$ signals in spectra are made on the basis of $1 D:\left({ }^{1} \mathrm{H},{ }^{13} \mathrm{C}, \mathrm{DEPT}-135^{\circ}\right)$ and $2 \mathrm{D}$ : homo$\left({ }^{1} \mathrm{H} /{ }^{1} \mathrm{H}\right.$ COSY-45 $\left.{ }^{\circ}, \mathrm{NOE}\right)$ and heteronuclear $\left({ }^{1} \mathrm{H} /{ }^{13} \mathrm{C} H S Q C, H S Q C-T O C S Y\right.$ and $\left.H M B C\right)$ experiments.

${ }^{b} 400 \mathrm{MHz}$.

${ }^{c} 100 \mathrm{MHz}$.

d300 $\mathrm{MHz}[6]$.

e $75 \mathrm{MHz}[6]$.

b,c Bruker Avance 400 spectrometer.

*Unclear signal pattern due to overlapping.

**Data are not reported.

\section{Conclusions}

The influence of the iridoid glycosides extract from Linaria genistifolia (L.) Mill. has been investigated on the resistance of the winter wheat Odesschi 51 plant to the caused by $F$. oxysporum and $H$. avenae pathogenic fungi root rot. We have established, that the iridoid glycosides extract from this plant, containing four major known compounds: 5-O-allosylantirrinoside, antirrinoside, linarioside and 6- $\beta$-hidroxiantirride, can be successfully employed in biological control of the mentioned wheat pathogens: it stimulates wheat grains germination and embryonic root growth in conditions of fungal infection. ${ }^{1} \mathrm{H} \mathrm{si}{ }^{13} \mathrm{C}$ NMR characteristics of 5-O-allosylantirrinoside in Py- $d_{5}$ are for the first time presented. Structures of two conformers of 5-O-allosylantirrinoside in $\mathrm{D}_{2} \mathrm{O}$ and Py- $d_{5}$ solutions are proposed, based on the experimental NMR data and molecular modelling studies.

\section{Experimental}

Obtaining the IGE

IGE from L. genistifolia were extracted from the dried aerial part of the plant $(300 \mathrm{~g})$, which was chopped and then subjected to reflux ( $3 \times 6$ hours in a $60 \%$ methanol aqueous solution, $3 \times 1.5 \mathrm{~L}$ ). The extracts were combined and concentrated 
through vacuum distillation, thereupon, the aqueous residue was decanted with chloroform; the aqueous fraction was passed through Sephadex LH-20. The column was eluted with 10\% aqueous methanol and the resulting eluate was evaporated through vacuum distillation to dryness. The dry residue $(4.6 \mathrm{~g})$ contained a mixture of components, the iridoid glycosides $\mathbf{1 - 4}$ being detected in it as major products by thin-layer chromatography on silica gel. For investigation of the biological properties, IGE extract has been employed as such; 5-O-allosyilantirrinoside $\mathbf{1}$ was its predominant component. For the identification of individual mixture components, a portion of it $(0.6 \mathrm{~g})$ was separated by column chromatographic method, by using silica gel $(40 \times 100 \mu \mathrm{m}$, Merck) with a solvent systems of chloroform/methanol (4:1) and chloroform/methanol/ water (95:5:0 $\rightarrow 10: 4: 1$ ), and then Sephadex LH-20 with the elution system methanol/water (1:9). After chromatographic isolation compounds 1 - 4 were obtained in the following amounts: 1- $52.4 \mathrm{mg}, 2-36.6 \mathrm{mg}, 3-32.8 \mathrm{mg}$, 4- $27.5 \mathrm{mg}$. By ${ }^{1} \mathrm{H}$ and ${ }^{13} \mathrm{C}$ NMR spectroscopy and via comparison with bibliographic data the IGE components $\mathbf{1}-\mathbf{4}$ were identified as follows: 1 - 5-O-allosylantirrinoside; 2 - antirrinoside; 3 - linarioside; 4 - 6- $\beta$-hidroxiantirride.

\section{Testing the biological activity of IGE}

F. oxysporum and $H$. avenae fungi stems were isolated from the stem of the winter wheat stem that manifested disease symptoms (brown spots), on a solid nutrient medium $\underline{\text { Potato }}$ Dextrose $\underline{\text { Agar }}$ (PDA) and identified trough macro and microanalysis. F. oxysporum and $H$. avenae fungi $\mathrm{CF}$ were obtained by inoculating mycelium in a Czapex Dox liquid medium and cultivating it, afterwards, for 21 days at temperatures of $22 \ldots 24^{\circ} \mathrm{C}$ [19].

Prior to sowing, the grains were soaked for 4 hours in aqueous solutions of IGE from L. genistifolia (L.) Mill. or Moldstim with the mass fractions of $10^{-5}, 10^{-4}, 10^{-3}$ and $10^{-2} \%$. As a control version the water soaked grains were employed. After drying the seeds for 24 hours, part of them was soaked for 18 hours in F. oxysporum CF, while another part was soaked in $H$. avenae CF for 21 days then they were rinsed twice with distilled water and placed in a Petri dish on moistened with distilled water filter paper. The seedlings were cultivated for 6 days at a temperature of $22^{\circ} \mathrm{C}$. The plant response was assessed based on its germination capacity and embryonic root length. For determination the germination capacity the wheat grains (100 pieces) were soaked for 24 hours in water then placed in sterile Petri dishes on moistened with distilled water filter paper. Germination was carried out in a climate chamber at a temperature of $20^{\circ} \mathrm{C}$, the number of germinated seeds being determined on the $7^{\text {th }}$ day. The experiments were run 5 times. Data were processed by STATISTICA 7 program.

\section{References}

1. Stojanov, N. Our Medicinal Plants. Nauka i Iskustvo: Sofia, 1973, Part II, 99p.

2. Baytop, T. Therapy with Medicinal Plants (Past and Present), 2nd ed. Nobel Tip Kitabevleri Ltd., Istanbul, 1999, $373 \mathrm{p}$.

3. San Feliciano, A.; Gordaliza, M.; Del Corral, J.M.M.; De La Puente, M.L. Neo-clerodane diterpenoids from roots of Linaria saxatilis var. Glutinosa. Phytochemistry, 1993, 33, pp. 631-633.

4. Handjieva, N.V.; Ilieva, E.I.; Spassov, S.L.; Popov, S.S. Iridoid glycosides from Linaria species. Tetrahedron, 1993, 49, pp. 9261-9266.

5. Ilieva, E.I.; Handjieva, N.V.; Popov, S.S. Iridoid glucosides from Linaria vulgaris. Phytochemistry, 1992, 31(3), pp. 1040-1041.

6. Ilieva, E.; Handjieva, N.; Spassov, S.; Popov, S. 5-O-allosylanirrinoside from Linaria species. Phytochemistry, 1993, 32(4), pp. 1068-1070.

7. Ercil, D.; Sakar, M. K.; Del Olmo, E.; San Feliciano, A. Chemical constituents of Linaria aucheri. Turkish Journal of Chemistry, 2004, 28, pp. 133-139.

8. Kitagawa, I., Tani, T., Akita, K. Yoshika, I. On the constituents of Linaria laponica $\mathrm{M}_{\mathrm{IQ}}$ I. The structure of linarioside, a new chlorinated glucoside and identification of two related glucosides. Chemical and Pharmaceutical Bulletin, 1973, 21, pp. 1978-1987.

9. Mashcenko, N.; Kintia, P.; Gurev, A.; Marchenko, A.; Bassarello, C.; Piacente, S.; Pizza, C. Glycosides from Linaria vulgaris Mill. Chemistry Journal of Moldova, 2008, 3(2), pp. 98-100.

10. Grigoriev, M. F.; Zincenco, V. A.; Grigoriev, A. M. Manifestation of caused by Fusarium and helminthes root rot on barley varieties depending on the weather conditions of the year, reproduction and sowing dates. Bulletin of Timireazev Agricultural Academy, 2006, No. 3, pp. 41-45 (in Russian).

11. Jalieva, L.D. Species composition of root and basal rot pathogens of wheat. Micology and Phytopathology, 2001, 35(6), pp. 52-56 (in Russian).

12. Lazări, I. Chemical and biological preparations for protection and stimulation of plant growth. Stiinta: Chisinau, 1997, 230 p. (in Romanian).

13. Mascenco, N.; Lupascu, G.; Guriev, A.; Barba, A.; Gorincioi, E.; Gavzer, S. Procedure of treatment the winter wheat against Fusarium oxysporum. Decision to grant a patent Nr.7887 from 2014.08.25. (in Romanian).

14. Haasnoot, C.A.G.; De Leeuw, F.A.M.; Altona, C. The relationship between proton-proton NMR coupling constants 
and substituent electronegativities-I: An empirical generalization of the Karplus equation. Tetrahedron, 1980, 36(19), pp. 2783-2792.

15. Reich, H. J. Structure determination using NMR, 2014. http://www.chem.wisc.edu/areas/reich/chem605/

16. Silverstein, R. M.; Webster, F. X.; Kiemle, D. J. Spectrometric identification of organic compounds. John Wiley \& Sons, Inc.: U.S.A., Seventh edition, 2005, 512 p.

17. Rahman, A.; Chouldhary, M.I. Solving problems with NMR spectroscopy. Academic Press, Inc.: San Diego, 1996, $430 \mathrm{p}$.

18. Scarpati, M. L.; Guiso, M.; Esposito, P. Iridoids (V). Structure and configuration of Antirrinoside. Gazzetta Chimica Italiana, 1968, 98, pp. 177-190 (in Italian).

19. Methods of experimental mycology. Naukova dumka: Kiev, 1982, 550 p. (in Russian). 